\title{
Pengelolaan Pekarangan Melalui Hatinya PKK Untuk Ketahanan Pangan Dalam Menghadapi Pandemi Covid-19
}

\author{
Agus Nugroho Setiawan $^{1^{*}}$ dan Septi Nur Wijayanti ${ }^{2}$ \\ ${ }^{1}$ Prodi Agroteknologi, Universitas Muhammadiyah Yogyakarta, \\ ${ }^{2}$ Prodi Hukum, Universitas Muhammadiyah Yogyakarta \\ *Corresponding Author : agusns@umy.ac.id
}

\begin{abstract}
ABSTRAK
Gondoarum, Wonokerto, Turi, Sleman berada di lereng selatan Gunung Merapi dengan lahan berupa tegalan tadah hujan. Pada beberapa tahun terakhir, lahan pertanian tanaman pangan di Gondoarum banyak mengalami penurunan karena ditanami salak pondoh. Menyiasati kondisi tersebut, salah satu alternatif solusinya adalah memanfaatkan halaman dan pekarangan rumah sebagai lahan budidaya tanaman melalui program Hatinya PKK. Untuk membantu mewujudkan Hatinya PKK di Gondoarum, dilakukan kegiatan pengabdian pada masyarakat dengan tujuan menjadikan pekarangan rumah menjadi lahan pertanian produktif, serta meningkatkan pengetahuan, wawasan dan ketrampilan masyarakat Gondoarum dalam mengelola lahan pekarangan untuk budidaya tanaman. Untuk mencapai target luaran sesuai tujuan, kegiatan pengabdian pada masyarakat dilakukan melalui beberapa tahapan mulai dari koordinasi dan sosialisasi kepada masyarakat, implementasi di lapangan, sampai monitoring dan evaluasi. Program pengabdian pada masyarakat telah berjalan dengan baik diikuti oleh pengurus dan anggota PKK, serta didukung oleh Ketua RT dan Kepala Dukuh Gondoarum, dengan dibimbing oleh Tim Pelaksana dosen dan mahasiswa UMY. Hasil pengabdian menunjukkan bahwa partisipasi masyarakat Gondoarum dalam kegiatan tinggi, masyarakat lebih terampil dalam pengelolaan pekarangan dan mampu mewujudkan Hatinya PKK yang produktif. Program Hatinya PKK di Gondoarum telah memberikan kemanfaatan yang luas dengan mampu menyediakan sebagian bahan pangan dari hasil panen di pekarangan terutama pada masa pandemi Covid-19.
\end{abstract}

Kata kunci: Ketahanan pangan, PKK, Pekarangan, Produktif

\begin{abstract}
Gondoarum, Wonokerto, Turi, Sleman is one village in the southern slope of Merapi Mountain with land in the form of rainfed fields. In the last few years, agricultural land for food crops in Gondoarum has decreased because it was planted with salak pondoh. Alternative solution is to use the yard for the cultivation of plants through the Hatinya PKK program. To help realize the Hatinya PKK in Gondoarum, community service activities was conducted with the aims of making the yard into a productive land, as well as increasing the knowledge, insight and skills of the Gondoarum community in managing the yard for plant cultivation. To achieve output targets according to objectives, community service activities was conducted through several stages from coordination and socialization to the community, implementation in the field, to monitoring and evaluation, guided by the UMY Lecturer and Student. The results of the community services showed that Gondoarum's community participation in activities is high, the community is more skilled in managing the yard and is able to create a beautiful, orderly, beautiful and comfortable, and productive yard. The Hatinya PKK Program in Gondoarum has provided extensive benefits by being able to provide some food from crops in the yard, especially during the Covid-19 pandemic
\end{abstract}

Keywords : Food security, PKK, Yard, Productive 


\section{PENDAHULUAN}

Gondoarum yang berada di Wonokerto, Turi, Sleman berada pada dataran tinggi dengan ketinggian tempat antara $700-800 \mathrm{~m}$ di atas permukaan laut. Lahan di Gondoarum sebagian besar berupa tegalan tadah hujan, dan sebagian lainnya dimanfaatkan untuk pemukiman penduduk kebun salak dan pekarangan (Anonim, 2019). Sejak beberapa tahun terakhir, lahan di Gondoarum pertanian tanaman pangan dan sayuran mengalami penurunan karena banyak ditamai salak pondoh. Padahal pangan merupakan kebutuhan pokok bagi kehidupan manusia, sehingga keberadaannya selalu dibutuhkan. Selama ini, bahan pangan dihasilkan dari sektor pertanian dengan memanfaatkan lahan pertanian produktif sebagai tempat budidaya tanaman (Setiawan \& Wijayanti, 2019). Untuk memenuhi kebutuhan pangan, masyarakat Gondoarum harus membeli di warung atau pasar sehingga menambah pengeluaran. Salah satu lahan yang potensial untuk pengembangan tanaman pangan adalah pekarangan dan halaman rumah. Halaman atau pekarangan rumah biasanya memiliki luas lahan terbatas, dan biasanya belum dimanfaatkan dengan optimal (Aligita et al., 2019).

Masyarakat Gondoarum sebenarnya sudah terbiasa mengelola lahan pertanian, namun pemanfaatan halaman dan pekarangan untuk budidaya tanaman pangan masih terbatas, karena keterbatasan pengetahuan dan keterampilannya. Menyiasati kondisi tersebut, salah satu alternatif solusinya adalah memanfaatkan halaman dan pekarangan rumah untuk budidaya tanaman melalui program Hatinya PKK (Halaman Asri, Teratur, Indah dan Nyaman Pembinaan dan Kesejahteraan Keluarga), yang merupakan gerakan masyarakat dengan memanfaatkan halaman di sekitar rumah dengan tanaman pangan dan tanaman keras, tanaman obat keluarga (TOGA) minimal untuk memenuhi keperluan dan tabungan keluarga, serta tanaman hias yang berfungsi untuk keindahan dan kenyamanan rumah (Anonim, 2017).

Pekarangan berpotensi untuk dikembangkan sebagai lumbung pangan sebab letaknya yang dekat dengan pemukiman sehingga pengelolaannya dapat dilakukan lebih intensif sehingga harapannya hasilnya lebih baik (Setiawan \& Wijayanti, 2019). Selain untuk tujuan produksi, halaman dan pekarangan yang dikelola dengan baik akan menjadi lebih asri dan nyaman (Khomah \& Fajarningsih, 2016) serta dapat meningkatkan pendapatan keluarga (Nurlina et al., 2019). Dalam jangka panjang diharapkan masyarakat yang mengelola pekarangan dapat hidup lebih sejahtera serta memberikan nilai positif pada penekanan pengeluaran biaya rumah tangga (Suaedi et al., 2013). Oleh karena itu, untuk mewujudkan Program Hatinya PKK di Dukuh Gondoarum dilakukan kegiatan pengabdian pada masyarakat dengan tujuan menjadikan pekarangan rumah di Gondoarum menjadi lahan pertanian produktif, serta meningkatkan pengetahuan, wawasan dan ketrampilan masyarakat Gondoarum dalam mengelola lahan pekarangan untuk budidaya tanama.

\section{METODE}

Pengabdian pada masyarakat di Gondoarum dilakukan dengan menerapkan beberapa metode, yaitu pendidikan masyarakat, konsultasi, difusi ipteks, dan pelatihan (Atmanto et al., 2015). Pendidikan kepada masyarakat yaitu pendidikan luar sekolah yang dilaksanakan dalam upaya pengembangan, penyebarluasan, dan penerapan ipteks untuk pembangunan melalui peningkatan kemampuan sumber daya manusia dalam menangani dan memecahkan berbagai masalah yang dihadapinya (Riduwan, 2016). Konsultasi diperlukan untuk memotivasi masyarakat Gondoarum agar terus memanfaatkan potensi, memelihara, mengembangkan dan memanfaatkannya pekarangan dengan baik. Difusi Ipteks diperlukan untuk percepatan penerapan teknologi budidaya tanaman yang mudah diadopsi masyarakat. Pelatihan diperlukan untuk meningkatkan ketrampilan masyarakat khususnya PKK dalam mengelola pekarangan.

Secara teknis pengabdian pada masyarakat dilakukan melalui beberapa tahapan mulai dari koordinasi dan sosialisasi kepada masyarakat, implementasi di lapangan yang meliputi penyuluhan, pelatihan, praktek pengelolaan pekarangan, pendampingan, sampai monitoring dan evaluasi, dengan peserta Pengurus dan anggota PKK, Kepala Dukuh, Ketua RT dan Ketua RW, serta dibantu pemudapemudi Gondoarum. Pada tahapan awal dilakukan koordinasi dan sosialisasi kepada masyarakat. Selanjutnya dilakukan penyuluhan, pelatihan, praktek pengelolaan pekarangan, pendampingan, serta monitoring dan evaluasi. Penyuluhan dilakukan dengan mengumpulkan 
anggota PKK untuk mendapatkan penjelasan tentang pemanfaatan dan pengelolaan pekarangan dan halaman rumah. Pelatihan dilakukan dengan cara demonstrasi dan latihan pemanfaatan dan pengelolaan pekarangan dan halaman rumah. Setelah penyuluhan dan pelatihan, dengan dibimbing oleh Tim Pelaksana, anggota PKK melakukan praktek pemanfaatan dan pengelolaan pekarangan dan halaman rumah. Pendampingan dilakukan dengan melakukan kunjungan ke masyarakat secara berkala dengan memberikan pembinaan dan konsultasi. Monitoring dan evaluasi dilakukan untuk mengetahui keberhasilan masyarakat dalam praktek pemanfaatan dan pengelolaan pekarangan dan halaman rumah.

\section{HASIL DAN PEMBAHASAN}

Pengabdian pada masyarakat di Gondoarum dilakukan selama 6 bulan mulai bulan Januari 2020 melalui beberapa tahapan, yaitu koordinasi, sosialisasi, penyuluhan, pelatihan, pendampingan, serta monitoring dan evaluasi. Secara umum kegiatan pengabdian pada masyarakat ini sangat bermanfaat terutama setelah WHO menetapkan Covid-19 sebagai pandemi (Kemenkes, 2020). Dampak akibat Covid-19 dirasakan seluruh penduduk dunia dan menyentuh seluruh aspek kehidupan. Dampak dari Covid-19 juga dirasakan di bidang pertanian dalam penyediaan bahan pangan sebagai kebutuhan utama manusia. Pembatasan sosial menyebabkan aktivitas petani dalam mengelola lahan pertanian menjadi terbatas, sehingga pengelolaan halaman dan pekarangan rumah menjadi sebuah alternatif yang baik untuk memenuhi kebutuhan pangan masyarakat (Setiawan \& Wijayanti, 2019).

Kegiatan pengabdian pada masyarakat di Gondoarum diawali dengan koordinasi baik secara internal oleh Tim pelaksana dosen dan mahasiswa, serta koordinasi eksternal antara Tim Pelaksana dengan Kepala Dukuh dan PKK Gondoarum untuk menentukan tahapan dan jadual kegiatan, yang dilakukan pada awal Bulan Januari 2020.

Kegiatan sosialisasi dilakukan untuk memberikan gambaran umum kegiatan pengabdian pada masyarakat, disampaikan oleh Tim Pelaksana dengan dihadiri oleh segenap pengurus dan anggota PKK Dukuh Gondoarum (Gambar 1). Pada kegiatan ini, Tim Pelaksana mengharapkan partisipasi aktif dan segenap anggota PKK karena kemanfaatan dari pengabdian pada masyarakat akan dirasakan oleh masyarakat Gondoarum.

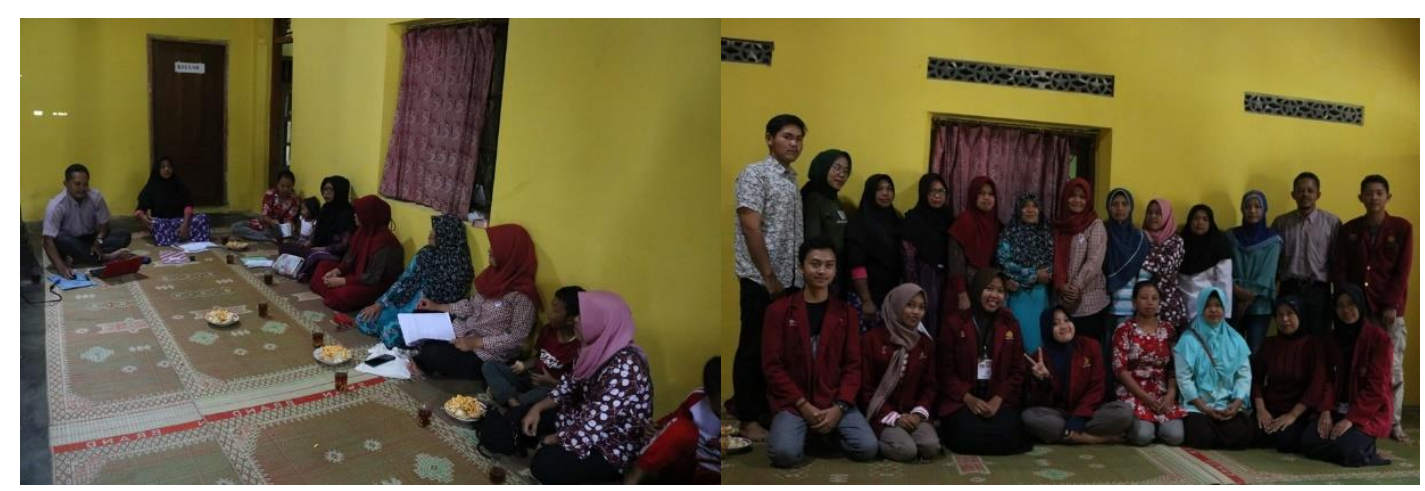

Gambar 1. Sosialisasi program PPM di Dukuh Gondoarum

Kegiatan penyuluhan dilakukan untuk memberikan pengetahuan dan wawasan ke PKK Gondoarum dengan materi pangan dan pengelolaan pekarangan, serta peran PKK dalam pengelolaan pekarangan. Penyuluhan dilakukan oleh Tim Pelaksana dan dihadiri oleh Kepala Dukuh, Ketua RT dan RW, serta pengurus dan anggota PKK. Untuk memudahkan dalam berkomunikasi dan meningkatkan keterserapan materi oleh peserta, penyuluhan dilakukan dengan Bahasa Indonesia dan Bahasa Jawa, mengunakan audiovisual dengan contoh gambar dan video tentang pengelolaan pekarangan dan pengalaman di beberapa daerah (Gambar 2), serta dibagikan buku "Pengelolaan Pekarangan" untuk menambah pengetahuan masyarakat (Ruyadi et al., 2017). Dalam penyuluhan ditegaskan agar masyarakat menerapkan sistem pertanian ramah lingkungan dan berbasis alam, karena sudah diterapkan sejak dahulu, serta dapat memanfaatkan potensi tanaman lokal yang ada di sekitar kebun sebagai pupuk organik (Puu et al., 2020). 


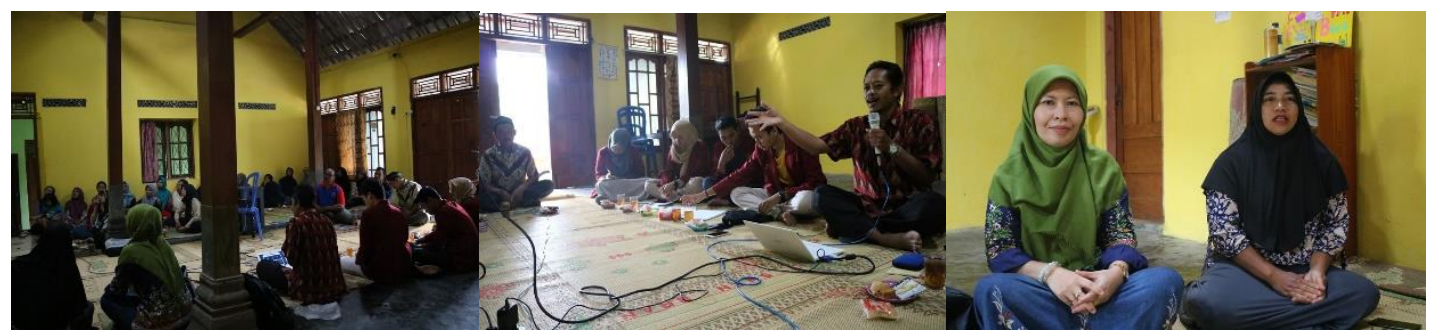

Gambar 2. Penyuluhan pengelolaan halaman dan pekarangan di Dukuh Gondoarum

Kegiatan praktek pengelolaan pekarangan diawali dengan penyiapan lahan. Tanah yang ada di Dukuh Gondoarum seperti halnya tanah yang berada di lereng Gunung Merapi berasal dari abu vulkanik dan didominasi oleh tanah muda (Regosol) dengan tekstur tanah yang kasar (pasiran) serta belum terbentuk struktur tanah yang baik dan bersifat granuler sehingga mudah kering (Utami et al., 2011). Oleh karena itu, tanah sebagai medium tanam perlu diberikan pupuk organik (kandang) agar lebih subur dan mampu menyimpan air lebih banyak (FAO, 2020). Tanah dicangkul agar gembur yang selanjutnya dicampur dengan pupuk kandang (Gambar 3). Meskipun tanah di Gondoarum termasuk tanah ringan karena banyak mengandung pasir sehingga mudah diolah, namun untuk pengolahan tanah banyak dikerjakan oleh bapak-bapak sebagai bentuk partisipasi dan dukungan terhadap PKK dalam pengelolaan lahan pekarangan (Gambar 3).

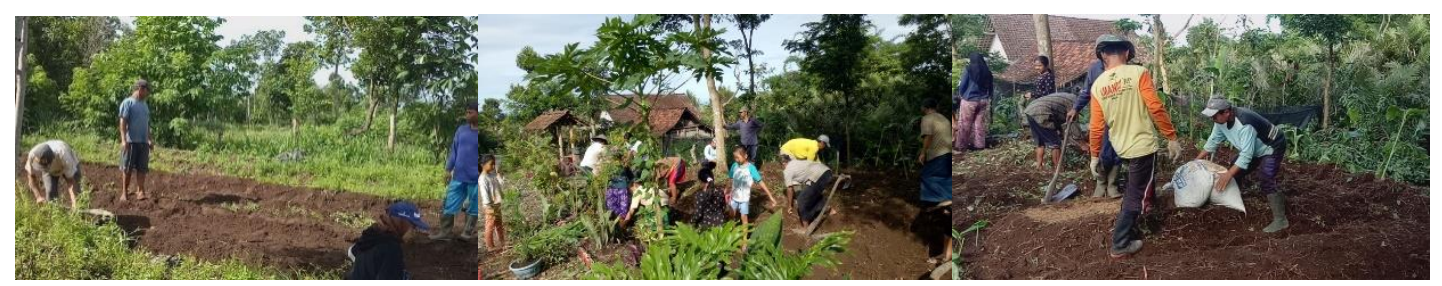

Gambar 3. Pengolahan lahan pekarangan untuk budidaya tanaman di Dukuh Gondoarum

Bibit yang akan ditanam di pekarangan Gondoarum dipilih sesuai dengan kebutuhan dan keinginan dari masyarakat, yaitu tanaman pangan (jagung), sayuran yaitu sawi, terong, cabai, serta tanaman obat yaitu sereh dan jahe, serta tanaman hias untuk estetika. Penanaman yang baik dilakukan pada pagi atau sore hari setelah lahan dan bibit siap (Edi \& Bobihoe, 2010), dengan di bimbing oleh Tim Pelaksana (Gambar 4).

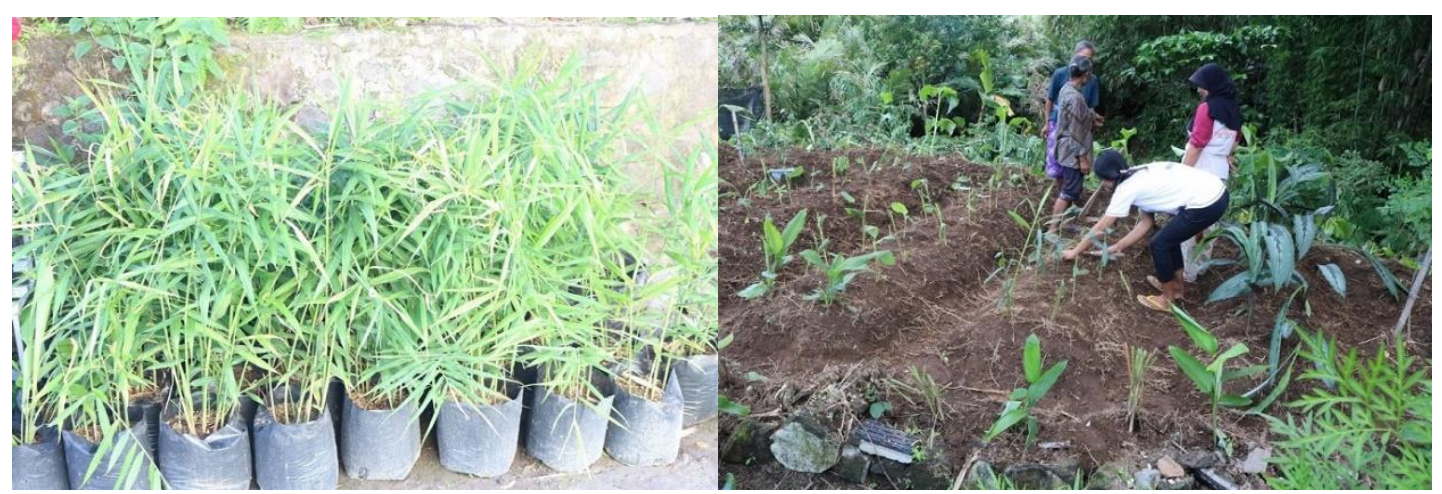

Gambar 4. Bibit dan kegiatan penanaman di lahan Dukuh Gondoarum

Sebagai bentuk antusiasme setiap RT, penanaman dilakukan dengan membuat kebun kelompok setiap RT, dengan jenis tanaman bervariasi dengan pola tanam monokultur (1 jenis tanaman) maupun polikultur (aneka jenis tanaman). Jenis tanaman yang berbeda tersebut menjadi ciri khas setiap RT sesuai dengan minat warga setempat (Gambar 5). Selain itu, beberapa kebun RT sebelum ditanami diberikan mulsa plastik hitam perak yang bertujuan untuk mengurangi kehilangan air akibat penguapan, menjaga kelembaban dan suhu tanah serta menekan pertumbuhan gulma (Basuki et al., 2009). 


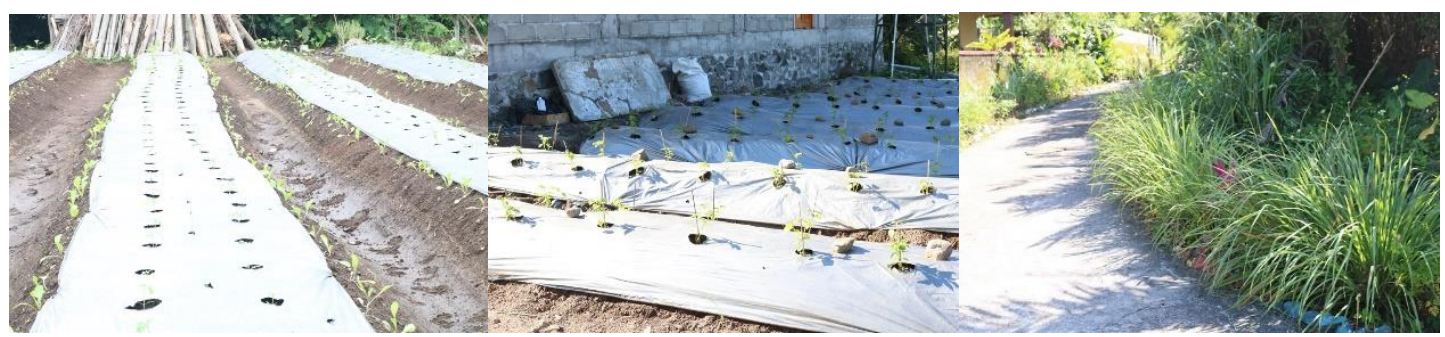

Gambar 5. Kebun kelompok dan pemanfaatan lahan di Dukuh Gondoarum

Penanaman juga dilakukan oleh warga dengan memanfaatkan halaman dan pekarangan secara mandiri, baik secara langsung di lahan atau menggunakan wadah polibag dengan jenis tanaman sesuai minat masyarakat (Gambar 6).
Beberapa warga masyarakat lebih memilih menanam sayuran karena dibutuhkan setiap hari, dan sebagian warga masyarakat yang lainnya memilih tanaman obat seperti jahe atau sereh.

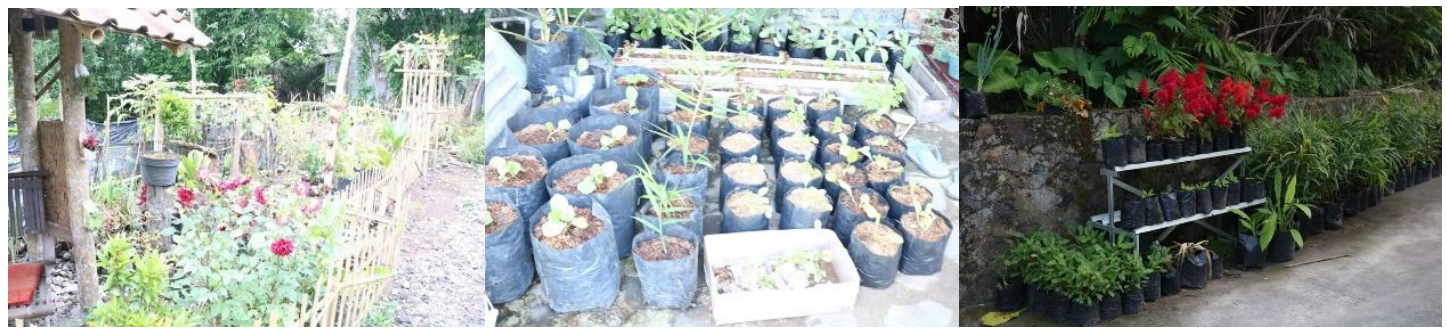

Gambar 6. Pemanfaatan lahan secara mandiri di Dukuh Gondoarum

Untuk mendapatkan pertumbuhan tanaman yang baik, dilakukan pemeliharaan dengan penyiraman, pemupukan, dan pengendalian hama. Meskipun Dukuh Gondoarum berada di daerah dataran tinggi, penyiraman tetap dilakukan terutama jika tidak banyak turun hujan untuk menjaga ketersediaan air bagi tanaman, dilakukan ketika suhu tanah sudah tidak tinggi lagi yaitu sore hari.

Untuk tanaman sayuran yang hasil akhirnya berupa daun, batang atau rimpang, dilakukan pemupukan susulan menggunakan pupuk nitrogen, baik menggunakan pupuk alami dari limbah rumah tangga seperti air cucian daging atau beras, maupun pupuk buatan pabrik berupa urea. Agar lebih efektif, pupuk diberikan dengan cara disempotkan melalui daun atau disiramkan melalui tanah. Pemeliharaan juga dilakukan dengan pengendalian hama secara manual karena tidak banyak hama yang menyerang.

Untuk mencapai hasil yang optimal, Tim Pelaksana melakukan pendampingan secara periodik dengan mengunjungi masyarakat dan kebun kelompok untuk monitoring dan evaluasi, Untuk meningkatkan partisipasi masyarakat dalam penerapan pemanfaatan lahan pekarangan, juga dilakukan kampanye dengan pemasangan banner ajakan pemanfaatan pekarangan kepada masyarakat di setiap RT untuk mewujudkan halaman asri, teratur, indah dan nyaman, serta produktif (Gambar 7).

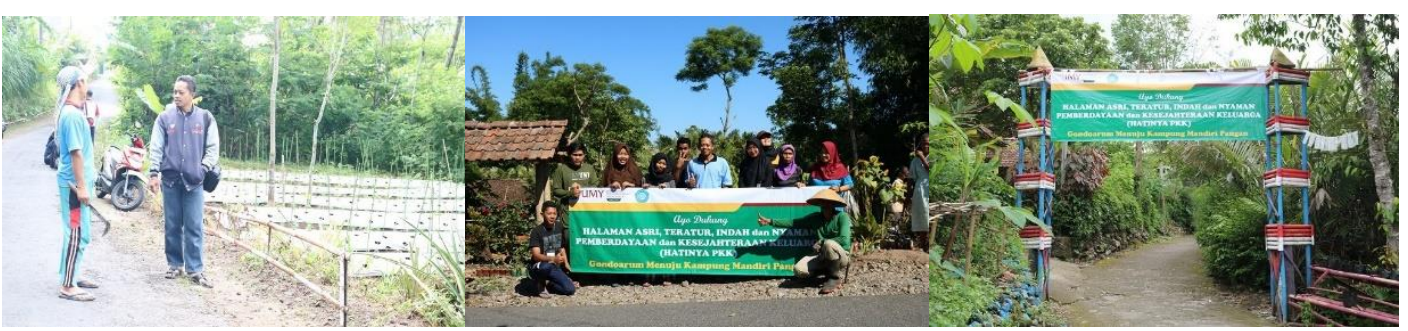

Gambar 7. Pendampingan dan kampanye Hatinya PKK di Dukuh Gondoarum

Dengan kerja bersama dan dukungan berbagai pihak, kegiatan pengabdian pada masyarakat di Gondoarum mampu mewujudkan halaman dan pekarangan yang produktif, dan diproyeksikan oleh Pemerintah Kecamatan Turi untuk mengikuti Evaluasi (Lomba) Desa Unggulan bidang "Hatinya PKK" Tahun 2020. Namun karena adanya pandemi Covid-19, 
kegiatan tersebut belum dapat dilaksanakan. Meskipun demikian, semua yang sudah dilakukan oleh masyarakat Dukuh Gondoarum dengan pendampingan oleh Tim Pelaksana telah memberikan kemanfaatan yang luas. Ketika masyarakat dibatasi aktivitas bertani sebagai akibat Covid-19, masyarakat masih mampu menyediakan sebagian bahan pangan dari hasil panen di pekarangan. Pemilihan tanaman jahe dan sereh juga sangat bermanfaat karena diyakini mengandung berbagai senyawa yang berperan dalam menjaga dan meningkatkan imunitas tubuh terutama di masa pandemi Covid-19.

Secara keseluruhan, kegiatan pengabdian pada masyarakat Hatinya PKK di Gondoarum Dalam Mendukung Evaluasi Desa Unggulan Wonokerto, Turi, Sleman, DIY sudah terlaksana dan berjalan dengan baik dan memberikan kemanfaatan yang banyak terutama dalam kondisi pandemi Covid-19 seperti sekarang ini, antara lain meningkatnya pengetahuan dan ketrampilan dalam mengelola pekarangan, ketersediaan bahan pangan dari pekarangan, pemenuhan bahan obat-obatan tradisional dari kebun, dan sebagainya.

\section{KESIMPULAN}

Dari program pengabdian pada masyarakat tentang Hatinya PKK untuk ketahanan pangan di masa pandemi Covid-19 di Gondoarum, Wonokerto, Turi, Sleman, Sleman, DIY dapat disimpulkan bahwa kegiatan telah berjalan baik dengan beberapa kegiatan yaitu koordinasi, sosialisasi, penyuluhan, pelatihan dan praktek pengelolaan halaman dan pekarangan, pendampingan, serta monitoring dan evaluasi. Partisipasi masyarakat Gondoarum dalam kegiatan tinggi, masyarakat lebih terampil dalam pengelolaan pekarangan dan mampu mewujudkan halaman asri, teratur, indah dan nyaman, serta produktif. Program Hatinya PKK di Gondoarum telah memberikan kemanfaatan yang luas dengan mampu menyediakan sebagian bahan pangan dari hasil panen di pekarangan terutama pada masa pandemi Covid-19. Meskipun Gondoarum, Wonokerto, Turi tidak jadi mewakili Kecamatan Turi dalam Evaluasi Desa Unggulan Bidang Hatinya PKK tingkat Kabupaten Sleman, namun program Hatinya PKK telah memberikan kemanfaatan yang luas dengan mampu menyediakan sebagian bahan pangan dari hasil panen di pekarangan dalam masa pandemi Covid-19.

\section{UCAPAN TERIMA KASIH}

Ucapan terima kasih dan penghargaan yang setinggi-tingginya disampaikan kepada Rektor dan Kepala LP3M UMY yang telah memfasilitasi kegiatan pengabdian pada masyarakat, mahasiswa UMY yang telah membantu pelaksanaan di lapangan dan seluruh warga Padukuhan Gondoarum, Wonokerto, Turi, Sleman sebagai mitra yang telah berperan aktif dalam berbagai kegiatan, dan semua pihak yang membantu sejak perencanaan sampai evaluasi hasil pengabdian pada masyarakat ini.

\section{DAFTAR PUSTAKA}

Aligita, W., Muttaqin, F. Z., Muhsinin, S., Febrina, E., \& Asnawi, A. (2019). Peningkatan Potensi Anggota KWT dalam Pemanfaatan Pekarangan untuk Tanaman Obat dan Kosmetika Menggunakan Metode Tanam Vertikal di Desa Cibiru Wetan , Kabupaten Bandung. Jurnal Pengabdian Pada Masyarakat, 4(4), 401408.

https://doi.org/10.30653/002.201944.187

Anonim. (2017). Peranan PKK dalam peningkatan pemanfaatan lahan pekarangan sebagai upaya kesejahteraan keluarga dan rumah sehat. https://docplayer.info/48878191-Perananpkk-dalam-peningkatan-pemanfaatanlahan-pekarangan-sebagai-upayakesejahteraan-keluarga-dan-rumahsehat.html.

Anonim. (2019). Wonokerto_Wikipedia. https://id.wikipedia.org/wiki/Wonokerto, Turi,_Sleman?veaction=edit\&section=3

Atmanto, W. D., Danarto, S., \& Winarni, W. W. (2015). Pemberdayaan karang taruna untuk kelola potensi pesisir desa bulakbaru kabupaten jepara. Indonesian Journal of Community Engagement, 01(01), 24-38. https://doi.org/10.22146/jpkm.16927

Basuki, J., Yunus, A., \& Purwanto, E. (2009). Peranan Mulsa Dalam Meningkatkan. Partner, 16(2), 73-77. ps://media.neliti.com/media/publications/ 156757-ID-peranan-mulsa-dalammeningkatkan-pertumb.pdf

Edi, S., \& Bobihoe, J. (2010). Budidaya Tanaman Sayuran. http://jambi.litbang.pertanian.go.id/ind/im ages/PDF/bookletsayuran10.pdf

FAO. (2020). GAP Budidaya Cabai yang Baik 
dan Benar. http://www.fao.org/3/abe829o.pdf

Kemenkes, R. I. (2020). Pedoman pencegahan dan pengendalian coronavirus disease (covid-19) revisi ke-4 1 https://www.kemkes.go.id/resources/down load/info-terkini/COVID-19 dokumen resmi/REV-04_Pedoman_P2_COVID-19_ 27 Maret2020_ Tanpa TTD.pdf.pdf.

Khomah, I., \& Fajarningsih, R. U. (2016). Potensi dan prospek pemanfaatan lahan pekarangan terhadap pendapatan rumah tangga. Proceeding Seminar Nasional Peningkatan Kapabilitas UMKM Dalam Mewujudkan UMKM Naik Kelas, 155161. kumkm.lppm.uns.ac.id/wpcontent/uploads/sites/21/2016/11/istikhomah_1.pdf

Nurlina, Adnan, \& SafrIzal. (2019). Pemanfaatan Lahan Pekarangan Dalam Meningkatkan Pendapatan Keluarga Pada Desa Blang Batee Kabupaten Aceh Timur. Global Science Society: Jurnal Ilmiah Pengabdian Kepada Masyarakat, 1(1), 97 107. https://ejurnalunsam.id/index.php/

Puu, Y. M. S. W., Saga, Ana, A. J. P., Djata, Taruma, B., \& Mutiara, C. (2020). Pemberdayaan Masyarakat Petani dalam Pengelolaan Pupuk dan Pestisida Organik dari Tanaman Lokal di Desa Wolofeo Kecamatan Detusoko Kabupaten Ende. $3(2), 43-49$.

Riduwan, A. (2016). Pelaksanaan Kegiatan Pengabdian Kepada Masyarakat Oleh Perguruan Tinggi. Ekuitas (Jurnal Ekonomi Dan Keuangan), 3(2). https://www.researchgate.net/publication/ 313778436_Pelaksanaan_Kegiatan_Penga bdian_Kepada_Masyarakat_Oleh_Perguru an_Tinggi

Ruyadi, I., Winoto, Y., Komariah, N., \& Padjadjaran, U. (2017). Media Komunikasi Dan Informasi Dalam Menunjang. 5(1), 37-50.

http://jurnal.unpad.ac.id/jkip/article/downl oad $/ 11522 / 5715$

Setiawan, A. N., \& Wijayanti, S. N. (2019). Desa mandiri pangan berbasis pekarangan di Donokerto, Turi, Sleman, DIY. Jurnal Adimas, 3(2), 16-22. https://doi.org/10.24269/ ADI.V3I2.1828

Suaedi, Nurhilal, \& Musindar, I. (2013). Peran Wanita Tani Dalam Pemanfaatan Lahan Pekarangan Untuk Tanaman Pangan. Jurnal Perbal, 2(3), 62-73. http://scholar.google.co.id/scholar_url?url =http://journal.uncp.ac.id/index.php/perba 1/article/view/59/55\&hl=en\&sa=X\&scisig =AAGBfm15ixJj6LDGm9haEMN94w1m -mfQ6g\&nossl=1\&oi=scholarr

Utami, S. N. H., Maas, A., Darmanto, Jayadi, R., E.Martono, Purwanto, B. H., Kusumandari, A., Murdjito, G., Marwasta, D., Jamhari, \& Kastono, D. (2011). Pengelolaan Lahan Kawasan Lereng Merapi Pasca Erupsi 2010. Makalah Focus Group Discussion Peruntukan Lahan Produksi dan Konservasi Pasca Erupsi Merapi (p. 13). http://faperta.ugm.ac.id/download/publika si_dosen/sri_nuryani/pdf/Pengelolaan Lhn Kwsan Lereng Merapi (Bb 20).pdf 